\title{
Not All Enlarging Papillary Microcarcinomas Under Active Surveillance Require Immediate Surgery
}

\section{Tyler Drake}

\begin{abstract}
Division of Endocrinology and Metabolism; Department of Medicine; Minneapolis VA Healthcare System; University of Minnesota Medical School; Minneapolis, MN, U.S.A.
\end{abstract}

Review of: Ito Y, Miyauchi A, Kudo T, Higashiyama T, Masuoka H, Kihara M, Miya A 2019 Kinetic analysis of growth activity in enlarging papillary thyroid microcarcinomas. Thyroid. Epub 2019 Nov 21. PMID: 31650907.

\section{SUMMARY}

\section{Background}

Active surveillance of papillary thyroid microcarcinomas (PMCs), defined as tumors measuring 10 $\mathrm{mm}$ or less, is becoming more common owing to ongoing studies reported from Japan, South Korea, and the United States (1-4). The 2015 American Thyroid Association guidelines on the management of thyroid nodules and differentiated thyroid cancer recommend considering active surveillance in patients with very-low-risk tumors such as PMCs without evidence of metastases, local invasion, or aggressive cytology (5). While under active surveillance, conversion surgery is generally recommended when there is either growth of $\geq 3 \mathrm{~mm}$ in the largest tumor dimension or an increase of $\geq 50 \%$ in tumor volume, depending on the medical center performing the monitoring (1-4).

\section{Methods}

This was a single-center retrospective study of 824 patients with PMC enrolled in active surveillance at Kuma Hospital in Japan between 2005 and 2011 (6). The median follow-up period was 6.04 years. All patients were diagnosed with PMC by cytology, and tumors were actively surveilled using thyroid ultrasound at least once per year. Significant growth, referred to as the point of enlargement, was defined as the time at which the maximal tumor size increased by $\geq 3 \mathrm{~mm}$ or the tumor volume increased by $\geq 50 \%$. When the primary tumor grew by $\geq 3 \mathrm{~mm}$, surgery was recommended; however, some patients requested continued active surveillance until the tumor reached an absolute maximal dimension of $13 \mathrm{~mm}$.

The primary outcome was the tumor-doubling rate (TDR), defined as the inverse of tumor-doubling time, in subjects who had significant tumor growth yet who continued to be monitored by active surveillance. The tumor-doubling rate was used to account for both positive (growing) and negative (shrinking) tumor-doubling times following the point of enlargement.

\section{Results}

Among the 824 patients enrolled, 92 had an increase in maximal tumor size of $\geq 3 \mathrm{~mm}$ and 333 had an increase in tumor volume of $\geq 50 \%$. In total, 83 patients underwent surgery. The 10-year enlargement-free survival rates based on maximal tumor size was $86.9 \%$ and on tumor volume $54.9 \%$. The tumor-doubling rates after the point of enlargement were significantly lower than those before the point of enlargement, for tumors $\geq 3 \mathrm{~mm} \quad(-0.091 /$ year vs. $0.509 /$ year, $\mathrm{P}<0.001$ ) and for those with $\geq 50 \%$ increase in volume $(-0.058 /$ year vs. 0.370/year, $\mathrm{P}<0.001)$. 
Following significant growth (defined as increase in tumor size by $\geq 3 \mathrm{~mm}$ ), $47.4 \%$ of nodules shrank, $32.1 \%$ remained stable, and $20.5 \%$ grew, with only $7.7 \%$ having rapid growth (defined as tumor-doubling rate $>0.5$ ). Following significant growth (defined as an increase in tumor volume by $\geq 50 \%$ ), $36.1 \%$ of nodules shrank, $48.1 \%$ remained stable, and $15.9 \%$ grew, with only $3.8 \%$ having rapid growth. Similar findings were seen across all age groups.

\section{Conclusions}

The majority of PMCs have significantly decreased growth following initial enlargement, which would traditionally be recommended for conversion surgery. This decreased growth activity suggests that continued active surveillance may be considered to avoid unnecessary surgery in select appropriate patients.

\section{COMMENTARY}

This study (6) provides further support as the pendulum swings toward active surveillance and away from surgery for low-risk papillary thyroid carcinomas. Previous studies have shown that the majority of low-risk PMCs remain stable in size while under surveillance, with young age being a predictor for tumor growth (1-4). This study shows that when significant tumor growth does occur, it is highly likely that the tumor will stop growing and may even shrink, suggesting that continued active surveillance may be a consideration regardless of patient age. Currently, there is debate regarding how significant growth should be defined, whether it be $\geq 3 \mathrm{~mm}$ growth of the maximal tumor or $\geq 50 \%$ increase in the tumor volume (1-4); although the present study does not resolve this question, it does show that continued tumor growth will likely cease in both situations.
Strengths of this study are the well-established active surveillance cohort, the ability to study both maximum tumor size and tumor volume, and the relatively long length of follow-up. The major limitation is a selection bias created by patients who continued under active surveillance despite having significant tumor growth and therefore being recommended conversion surgery. The authors state that surgery was always recommended when the tumor reached $13 \mathrm{~mm}$ in size (6), yet other studies have used 15 $\mathrm{mm}$ to define low-risk tumors (4). As active surveillance becomes a more substantial mainstay in the treatment of low-risk thyroid cancers, studies will be needed to define the optimal timing of conversion surgery and the maximum tumor size appropriate for active surveillance.

\section{Refierences}

1. Ito Y, Miyauchi A, Kihara M, Higashiyama

T, Kobayashi K, Miya A 2014 Patient age is significantly related to the progression of papillary microcarcinoma of the thyroid under observation. Thyroid 24: 27-34.
2. Sugitani I, Toda K, Yamada K, Yamamoto N, Ikenaga M, Fujimoto Y 2010 Three distinctly different kinds of papillary thyroid microcarcinoma should be recognized: our treatment strategies and outcomes. World J Surg 34: 1222-1231. 
3. Oh HS, Ha J, Kim HI, Kim TH, Kim WG, Lim DJ, Kim TY, Kim SW, Kim WB, Shong YK, et al 2018 Active surveillance of low-risk papillary thyroid microcarcinoma: a multi-center cohort study in Korea. Thyroid 28: 1587-1594.

4. Tuttle RM, Fagin JA, Minkowitz G, Wong RJ, Roman B, Patel S, Untch B, Ganly I, Shaha AR, Shah JP, et al 2017 Natural history and tumor volume kinetics of papillary thyroid cancers during active surveillance. JAMA Otolaryngol Head Neck Surg 143:10151020.
5. Haugen BR, Alexander EK, Bible KC, Doherty GM, Mandel SJ, Nikiforov YE, Pacini F, Randolph GW, Sawka AM, Schlumberger M, et al. 2016 2015 American Thyroid Association management guidelines for adult patients with thyroid nodules and differentiated thyroid cancer: the American Thyroid Association Guidelines Task Force on Thyroid Nodules and Differentiated Thyroid Cancer. Thyroid 26:1-133.

6. Ito Y, Miyauchi A, Kudo T, Higashiyama T, Masuoka H, Kihara M, Miya A 2019 Kinetic analysis of growth activity in enlarging papillary thyroid microcarcinomas. Thyroid. Epub 2019 Nov 21.

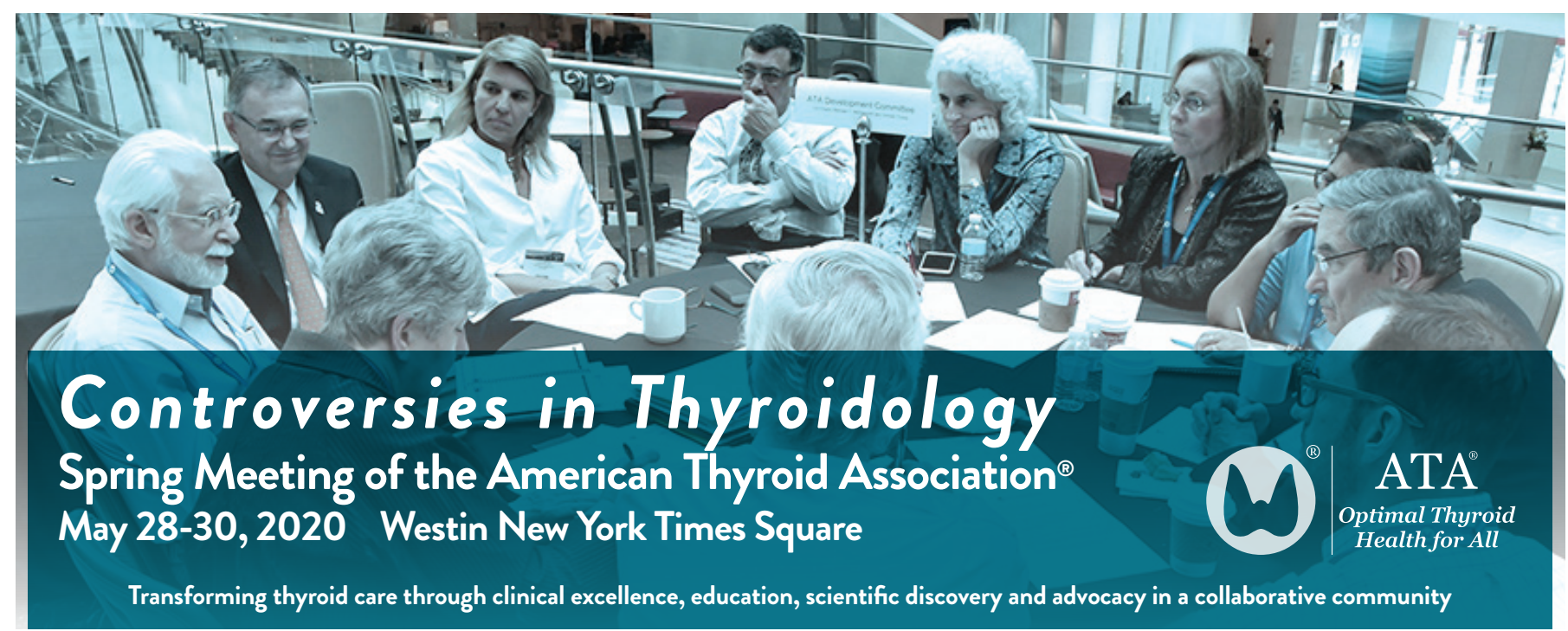

